\title{
Research Trend Analysis for Sustainable QR code use - Focus on Big Data Analysis
}

\author{
Eunji Lee ${ }^{1}$, and Jikyung Jang ${ }^{2 *}$ \\ ${ }^{1}$ Global Leaders College, Yonsei University \\ Seoul, South Korea \\ [e-mail: eun.ji.lee@yonsei.ac.kr] \\ ${ }^{2}$ Department of Business Administration, Dongseo University \\ Busan, South Korea \\ [e-mail: jkjang@dongseo.ac.kr] \\ *Corresponding author: Jikyung Jang
}

Received June 6, 2021; revised July 21, 2021; accepted August 4, 2021;

published September 30, 2021

\begin{abstract}
The purpose of the study is to examine the current study trend of 'QR code' and suggest a direction for the future study of big data analysis: (1) Background: study trend of 'QR code' and analysis of the text by subject field and year; (2) Methodology: data scraping and collection, EXCEL summary, and preprocess and big data analysis by R x 64 4.0.2 program package; (3) the findings: first, the trend showed a continuous increase in 'QR code' studies in general and the findings were applied in various fields. Second, the analysis of frequent keywords showed somewhat different results by subject field and year, but the overall results were similar. Third, the visualization of the frequent keywords also showed similar results as that of frequent keyword analysis; and (4) the conclusions: in general, 'QR code' studies are used in various fields, and the trend is likely to increase in the future as well. And the findings of this study are a reflection that 'QR code' is an aspect of our social and cultural phenomena, so that it is necessary to think that 'QR code' is a tool and an application of information. An expansion of the scope of the analysis is expected to show us more meaningful indications on 'QR code' study trends and development potential.
\end{abstract}

Keywords: Big data; QR code; Research Trend; Text Mining; R program; Network analysis 


\section{Introduction}

The global data market is expected to grow by 2,600 billion dollars by 2022, according to IDC, a global market research corporation [1]. With continuous development of Information and Communication Technology(ICT) and prevalent use of smartphones, our communication activities through social networking services, such as Twitter, Blogs and Facebook, are on an increasing trajectory. And these activities in return exponentially increase the amount of data traffic, so that 'big data' has become a social issue as a technology for analysis and processing of such vast amount of data [2].

Artificial Intelligence (AI) is also expected to contribute about 1.57 billion dollars to the global economy by 2030, according to Pricewaterhouse Coopers (PwC), a global consulting company. McKinsey also expects that artificial intelligence will contribute 1.3 billion dollars to the world economy, boosting global Gross Domestic Product (GDP) by $1.2 \%$ annually. But in the case of South Korea, there is, in fact, not enough processed data across the value chain in general, such as, contribution, distribution and utilization of big data, and the level of the availability of public data is relatively low as well. For example, U.S. has made 230,000 pieces of public data available to the public, while there are about 25,000 pieces of public data available to the public in South Korea, this is only $31^{\text {st }}$ place out of 63 countries [1,3]. But the utilization of 'googling' by Google and 'Naver lab' by Naver appear to be increasing rapidly, and this means that big data studies are continuously increasing regardless of the development level of public data.

The Korean government has a strategic plan to grow the domestic data market to 30 billion dollars and help create about 10 unicorn companies by 2030 with the budget of 6.8 billion dollars [4-6]. In 2020, the Korean government planned to build 10 big data platforms and 100 big data centers with the budget of 7.43 million dollars to establish private, public data by field $[1,2]$. According to the analysis of ICT-related major issues carried out by the National Information Society Agency of South Korea, AI/robot technology appears to be the most prominent topics in the fields of technology, sociology, economy and environment, and the other major topics include information security, block chain IoT, autonomous driving, fintech, big data and drones among others [4-6]. So, we can draw the conclusion that there is a high level of interest in big data and AI in various fields and big data can be applied to other fields as well.

Information communication technology (ICT) helped widespread use of smartphones, so that online information services developed mobile-based. Global mobile information service industry is expected to reach 274.4 billion dollars by 2021, an annual growth of $62 \%$ from 2016 to 2021, according to a report by STATISTA [5]. With the developments of mobile technologies, there have been various technological innovations, and a variety of technologies are used for mobile payment systems such as NFC (Near Field Communication), QR (Quick response), BLE (Bluetooth Low Energy) and MST (Minimum Spanning Tree).

In South Korea, QR code-based payment services were first initiated by Kakao, Co ltd, a social network platform, when they started 'Kakao pay' service in 2018, and QR-based offline payment service started when 'Zero Pay', government backed easy-to-use payment system for small business owners, started to provide payment services in first half of 2021. With the recent growth of contactless business activities, the use of QR code is spreading rapidly and into various fields. QR stands for quick response, and it uses two-way methods of information storage, vertical and horizontal. According to a report by Juniper Research, a British market research institute, it is estimated that about 1.3 billion QR codes were used in 2019 and the number is expected to reach 5.3 billion by 2022, so that 5.3 billion QR codes is expected to be 
used in 1.0 billon mobile devices [5,6]. The Korean government has a strong plan to support QR code adoption in the market, so that the potential for QR code related developments is very promising. With recent increase in contactless activities, in particular, the applications of the QR code are expected to expand into various fields.

In the study, therefore, we look at the trend of QR code studies and analyze the big data to propose a direction for future QR code utilization. When it comes to big data analysis, the advantages are that statistical analysis and test analysis are both available, and it is easy to have comprehensive view of the big picture because of its high level of visualization effects. Text analysis, in particular, is expected to help provide deep look into the use of QR code in the future. The findings of the study, therefore, are expected to contribute to formulation of the government regulations and policies by providing comprehensive view of QR code applications. The analysis process is as follows: first, the trend of QR code papers done over time and the current status of publications of the papers are examined by field. Second, the frequency analysis and words cloud analysis are carried out for the titles, abstracts, and keywords of the papers for their respective year and field.

\section{Literature Review}

\subsection{Big data}

Big data includes a large amount of unstructured data (tens of terabytes), beyond the control of traditional database, and big data technology is to derive value from the data and analyze the findings. In other words, it means vast amounts of data that can be difficult to process with a traditional database. According to existing studies, big data can be defined in various ways. According to Mckinsey's definition, big data is so big that it can’t be stored, managed, analyzed with legacy systems [2,3], while Gatner defines big data as a phenomenon in which various kinds of data are generated so fast that companies are not able to cope with it post $21^{\text {st }}$ century $[7,8]$. Kim, K.S. defines big data as completely new information environment where the diversity of data, the volume and storage speed, among others, completely different from those of the past [7]. According to Industrial Development Corporation (IDC), big data is next generation technology and architecture designed for fast capture, search and analysis of data to economically derive necessary value from vast amount of diverse data. Big data, in general, can be characterized by $4 \mathrm{~V}$, which are vast amounts of volume, diverse forms of data, velocity of data processing, and new value. The complexity of processing technology can be added as another attribute $[8,9]$.

There have been continuous big data related studies in various fields up to the present day. Early studies were mainly for the introduction of the concept of big data and definition [10$12]$, and then presented conceptual characteristics $[9,13]$. Then, they used data mining focusing on technology and analysis, and statistical analysis [14-16]. And the studies were relational analyses such as correlation, trend, and corporate performance analysis, and developments of new markets [15,17-19]. After the concept of big data became widely known, studies were carried out in connection with other technologies such as RFID or mobile phone [20]. Tiwari et al. (2018) analyzed big data focusing on supply chain management from 2010 to 2016 [21]. Jeon, J.Y. (2019) analyzed 'big data' key words related study trend in South Korea and did comparative study by subject and year to come up with suggests for future study direction [2]. In particular, a lot of innovation and big data analysis were carried out in connection with information and communication technology (ICT) [22-23]. And in recent years, 'tourism and leisure' trend was examined by corpus studies, together with trend studies on domestic fashion 
design. Tiwari et al. (2018) expanded trend study into overseas medical and manufacturing fields [21,24-27]. Kim et al. (2017) carried out topic modeling and Network analysis, based on aerial study materials [28].

In this study, the trends are examined by looking at QR code or QR code-related key words, and title, abstract, or keyword-related frequent key words are analyzed with text mining to illuminate current study trends and to suggest a direction for future studies.

\subsection{QR code}

QR code is abbreviation for Quick Response Code developed by DENSO WAVE (1994), a Japanese company, which is one of two-dimensional coding technologies. Unlike bar code which stores information in one direction only, QR code can store information in two directions, vertical and horizontal, so that it can dramatically increase the amount of information storage [17]. QR codes can process all sorts of data, such as Korean characters, English letters, Chinese characters, symbols, numbers, control codes, binary notation, among others. A QR code can store up to 4,296 letters, 1,817 Korean or Chinese characters, 7,089 numbers and 2,953 digits for binary code [18]. That is, it has an advantage of storing a large amount of information.

QR code is standardized in its global application. The advent of contactless era and the technological development in QR code together led an expansion of the applications of QR code in varies fields. Especially, with increasing use of smartphones with QR scanner and expanding Wi-Fi coverage, the applications of QR code have expanded into various types of contents beyond existing text-oriented contents. QR code can immediately respond to needs of the users and provide more accurate, in depth information [29]. Unlike existing one directional communication, QR code can offer bidirectional communication in connection with multimedia (twitter and Facebook, etc.).

Even though QR code studies have taken places in various fields, QR code has been considered just a field of technology, so it has not been able to generate much interest among researchers in general. But with the recent growth in noncontact activities and various mobilebased payment systems, the use of QR code has deeply infiltrated our daily life, and the scope of applications has been expanding to various fields, including education, medical, media, and advertisement among others. But despite such rapid growth of QR applications, systematic QR code studies have been lacking. 1980s witnessed the beginning of QR cord studies, but it wasn't until the 2000s that full-fledged QR code studies start to emerge. Early QR code studies were mostly introductory, but then the studies of QR code applications took off in various fields of industry in the latter part of the 2000s. For example, it began to be used as a way of information sharing in medical in 2008 [30], and in 2010, the studies were about applications for marketing [31], and for library and provision of education [32]. Since 2014, the studies were about applications for marketing and education textbook in connection with smartphones [33-34]. After 2015, the studies were about internet banking and electronic commerce and mobile payment systems [35-37, 38]. In 2017, many studies such as cold chain were carried out in the field of distribution system [21, 39].

But the limitations with existing studies are that they are restricted to certain industries so that it is relatively hard to take a comprehensive view on the wide range of applications of QR code in general. So, realizing the necessity of a comprehensive approach to QR code, this study uses various analytic approaches to QR code study to examine the applications more broadly for clearer analysis to suggest a direction for future studies. 


\section{Methodology and Analysis}

The query words used in the integrated search at site: www.riss.kr are 'QR', 'QR code' to find relevant study papers and the data are collected from the papers. Scraping method is used for analysis of the data from their English abstracts. For the examination of the latest trend, the 1st collection was completed on July 30, 2020, and the data was reorganized in December 2020. The papers collected totaled 393 and repetitive papers, irrelevant papers, papers without English abstracts were removed and of the resulting papers 354 were analyzed. According to the findings, 'QR code' related papers first appeared in 1999 and of the resulting papers 354 were classified by subject field and year.

For the examination of the existing studies, the numbers of research papers done by field over time are counted and text mining (TM), which is unstructured data analysis, is carried out for their respective field and year. And the detailed procedure is as follows: First, the current state of the papers by type is examined, and major study trends were investigated by subject field and year. The methods used are (1) text mining, a big data analytic technique, and relevant word analysis, and then (2) word cloud is used for the visual analysis of the data. The analytic packages used are R x 64 4.0.2 program and Rstudio. The analysis was carried out with TM, Stringr, Wordcloud, SnowballC, Tidymodels, Network, GGally, sna, RColorBrewer, ggplot2 among others. In particular, the titles and abstracts of the papers were considered, with unnecessary parts removed, such as special characters, numbers because abstracts are textbased, so only nouns are collected. The frequency of the noun words was examined with the data mining method. So, in this way, the general trends of the studies were examined, and they were examined by subject field and year to suggest a direction for future studies. Afore mentioned analyzes are summarized as Table 1.

Table 1. Analysis and Procedure

\begin{tabular}{|c|c|}
\hline Analysis & $\begin{array}{ll}\text { Procedure } \\
\end{array}$ \\
\hline Data scraping & $\begin{array}{c}\text { ·Data: Papers about ‘QR code’ } \\
\text { ·Period: July 30, 2020 December 31, } 2020 \\
\end{array}$ \\
\hline Preprocessing & $\begin{array}{c}\text {-1st: Organization of analyzed materials } \\
\text {-2nd: Extraction of nouns from Title / Abstract / Keyword } \\
\text {-3rd: Modification of text corpus (removal of } \\
\text { signs/numbers/articles/general terms) }\end{array}$ \\
\hline Frequency & $\begin{array}{c}\text {-Selection of keywords that appear } 10 \text { times or more. } \\
\cdot \text { Matrix of analyzed keywords } \\
\cdot \text { Extraction of keywords through } 50^{\text {th }} \text { rank }\end{array}$ \\
\hline Network analysis & ·Analysis of relationship among keywords \\
\hline Text visualization & - Visualization of wordcloud through frequency analysis \\
\hline Comparative analysis & $\begin{array}{c}\cdot \text { Analysis of keywords change by subject field } \\
\cdot \text { Analysis of keywords change by year } \\
\end{array}$ \\
\hline
\end{tabular}

\section{Results}

\subsection{The general picture of QR code papers}

Fig. 1 below is the current state of QR code related papers that appeared in academic journal for the sample period. Looking at the changes in the number of the studies for the 20-year period of 1999-2020 shows that the number dramatically increased since 2010, but then the increase slowed before the growth resumed in 2017. However, the sample period of this study is through August, 2020, so that the trend must be upward. 


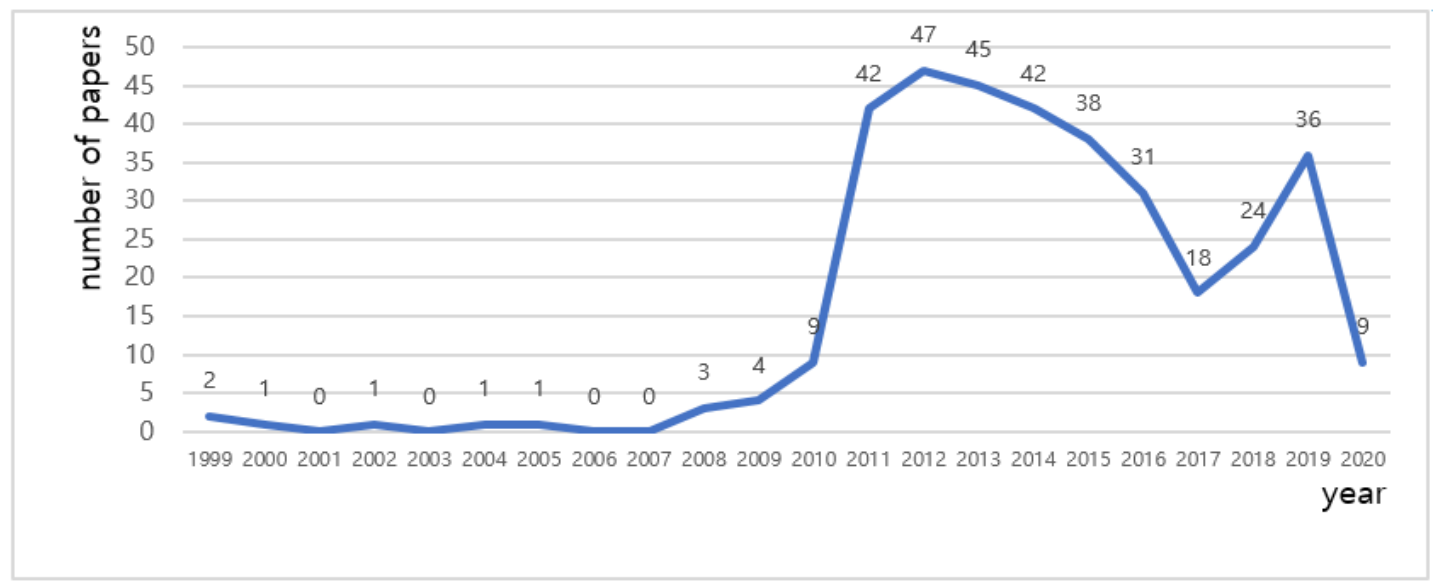

Fig. 1. Publication of QR code related papers by year

Table 2 below presents the summary of QR code related papers by subject field. A total of 10 subject fields are investigated, but science and technology subjects appear to be the highest at $25.7 \%$, followed by interdisciplinary science (18.1\%), social science $(16.1 \%)$, and art and physical education (11.03\%). As indicated in Fig 1, QR code papers have increased since 2010. And this is due to the fact that the year 2010 witnessed dramatic increase in the disseminations of smartphones, such as iPhone. The popularity of smartphones brought about fast dissemination of information, and this paved a way for the evolution of the concept of barcode to the concept of QR code. So, more studies in science and technology and convergence are expected to come now on. In addition, in this examination by subject field, the top 6 are examined for their study trend by year and Fig. 2 below presents the findings. According to Fig. 2, there had been few studies about QR code in all subject fields before 2010. But then a dramatic increase was observed in most of the subject fields since 2010. Since then, the number of studies by subject field fluctuated over the different time periods, but after the dramatic increase after 2010, it decreased in 2017 and then it has trended up to the present day.

Table 2. Paper publication by subject field

\begin{tabular}{|c|c|c|}
\hline Subject fields & Number of papers & Ratio (\%) \\
\hline \hline Social science & 57 & 16.1 \\
\hline Engineering & 53 & 15.0 \\
\hline Art and physical education & 40 & 11.3 \\
\hline Science and technology & 91 & 25.7 \\
\hline Humanities & 29 & 8.2 \\
\hline Medicine and pharmacy & 1 & 0.3 \\
\hline Natural science & 4 & 1.1 \\
\hline $\begin{array}{c}\text { Agriculture, fisheries, and } \\
\text { oceanography }\end{array}$ & 8 & 2.3 \\
\hline Interdisciplinary science & 64 & 18.1 \\
\hline Generic & 7 & 2.0 \\
\hline Total & 354 & 100.00 \\
\hline
\end{tabular}

Specifically, in the fields of 'science and technology' and 'interdisciplinary science', the number of studies increased after 2010 and culminated in 2021, after which the amount fluctuated greatly. In the fields of social science, engineering, art and physical education, the 
studies appeared to have been robust ever since 2010. But in the field of 'humanities', the increase in the studies was delayed compared to the other subject fields, and then the studies increased in 2014 and decreased in 2017 before it resumed its upward trend. Recent development has been complex, like science and technology, backed by the development of existing technology or engineering.

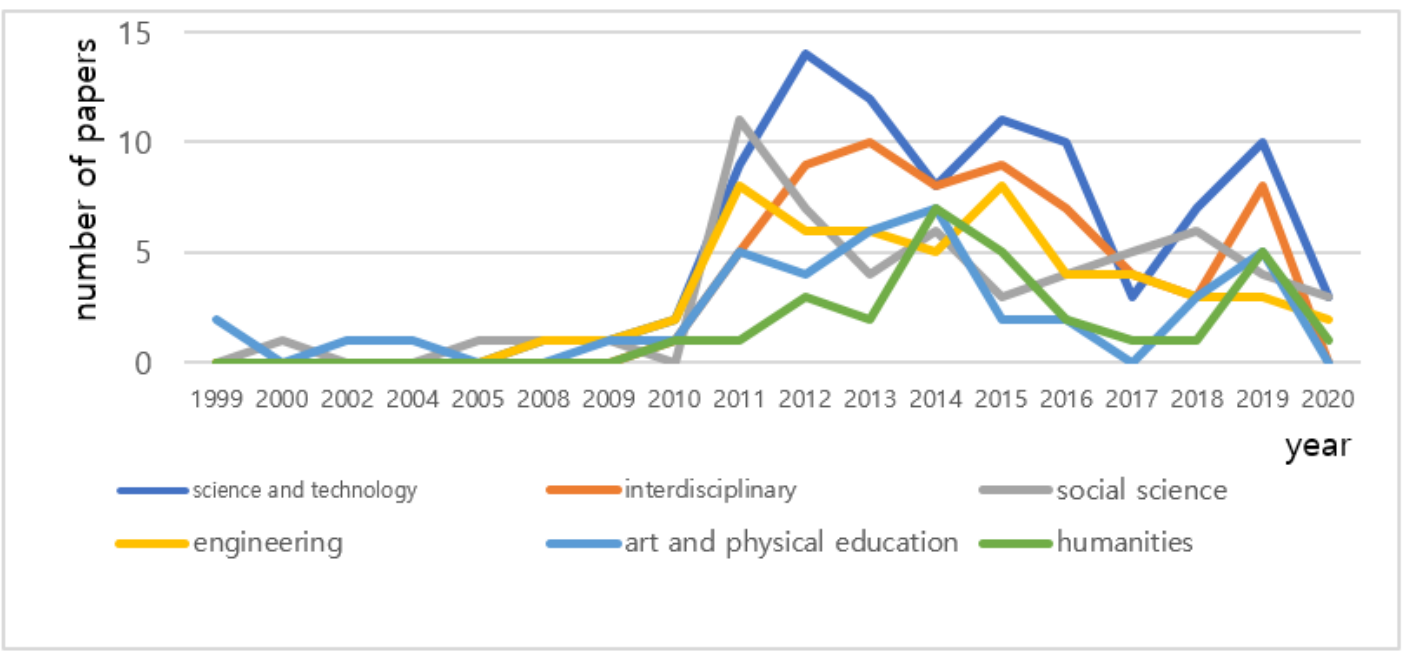

Fig. 2. Publication of 'QR code' related study papers by year

\subsection{Frequency Analysis of keywords and the finding}

\subsubsection{General frequency analysis of keywords}

Table 3 presents frequency analysis of the 'title,' 'abstract' and 'keyword' for the top 20 keywords. In the analysis of the keywords, the highest frequency word is 'qr', and the other high frequency words are 'code', 'system', 'using', 'information', 'smart', 'using' among others. When it comes to the title, relatively high frequency words are 'design', 'mobile', 'application' and for the abstract, the high frequency words are 'information' and 'use', 'used', 'method', and for the key word, the high frequency words are 'leaning', 'response' and 'image'.

Table 3. Frequency analysis of keywords

\begin{tabular}{|c|c|c|c|c|c|c|c|c|}
\hline \multicolumn{3}{|c}{ Title } & \multicolumn{3}{c|}{ Abstract } & \multicolumn{3}{c|}{ Keyword } \\
\hline No. & word & Freq. & No. & word & Freq. & No. & word & Freq. \\
\hline \hline 1 & qr & 165 & 1 & qr & 1023 & 1 & qr & 47 \\
\hline 2 & code & 130 & 2 & code & 799 & 2 & code & 46 \\
\hline 3 & using & 95 & 3 & information & 506 & 3 & learning & 15 \\
\hline 4 & system & 78 & 4 & system & 326 & 4 & system & 13 \\
\hline 5 & smart & 44 & 5 & using & 319 & 5 & smart & 10 \\
\hline 6 & design & 44 & 6 & codes & 276 & 6 & management & 9 \\
\hline 7 & mobile & 39 & 7 & smart & 243 & 7 & information & 9 \\
\hline 8 & development & 35 & 8 & mobile & 240 & 8 & response & 7 \\
\hline 9 & management & 35 & 9 & used & 207 & 9 & image & 7 \\
\hline 10 & application & 31 & 10 & use & 182 & 10 & education & 6 \\
\hline 11 & codes & 31 & 11 & method & 176 & 11 & security & 6 \\
\hline 12 & information & 28 & 12 & design & 165 & 12 & digital & 6 \\
\hline
\end{tabular}




\begin{tabular}{|l|c|c|c|c|c|c|c|c|}
\hline 13 & method & 23 & 13 & data & 163 & 13 & data & 5 \\
\hline 14 & model & 22 & 14 & technology & 154 & 14 & color & 5 \\
\hline 15 & implementation & 21 & 15 & users & 150 & 15 & recognition & 5 \\
\hline 16 & qrcode & 20 & 16 & various & 145 & 16 & codes & 5 \\
\hline 17 & recognition & 18 & 17 & learning & 142 & 17 & quick & 5 \\
\hline 18 & technology & 17 & 18 & management & 139 & 18 & payment & 4 \\
\hline 19 & digital & 17 & 19 & service & 131 & 19 & bar & 4 \\
\hline 20 & image & 15 & 20 & application & 130 & 20 & $\begin{array}{c}\text { transform/ } \\
\text { science/visual/ } \\
\text { medical/qrcode } \\
\text { /barcode }\end{array}$ & 4 \\
\hline
\end{tabular}

\subsubsection{Frequency analysis of keywords by subject field}

\section{(1) Frequency analysis of 'title' by subject field}

Table 4 below presents the result of the frequency analysis of keywords by subject field for the 'title'. Table 4 presents a summary of the top 20 keywords by subject field, and the common frequency keywords across the subject fields are 'qr', 'code', 'using', 'smart' and 'system'. For the fields of 'science and technology', top ranking keywords are 'design', 'implementation' and 'mobile'; for the 'interdisciplinary' field, top ranking keywords are 'codes', 'fashion' and 'two-dimensional'; for the field of 'social science', top ranking keywords are 'consumer', 'application', 'model'; for the 'engineering' field, the keywords are 'mobile', 'robot', 'algorithm' and 'camera'; the keywords derived from the field of 'art and physical education' are 'marketing', 'construction'; and for field of 'humanities', the keywords derived are 'learning', 'education', 'elementary' and 'school'.

According to the findings, high ranking key words are related to mobiles, applications, and information in fields of 'science technology', 'interdisciplinary', 'social engineering', 'engineering', and the growth is expected to be more prominent in industries related to smartphone settlement and distribution. The keywords are extracted with regard to information provision and learning in the fields of humanities, arts, and physical education as well, and this means that QR code is expected to be used for the formulation of strategies and educational contents in corporate businesses and educations as well.

Table 4. Frequency analysis of keywords by subject field for the title

\begin{tabular}{|c|c|c|c|c|c|c|}
\hline \multirow{2}{*}{ No. } & \multicolumn{2}{|c|}{ Science and technology } & \multicolumn{2}{c|}{ Interdisciplinary science } & \multicolumn{2}{c|}{ Social science } \\
\cline { 2 - 7 } & word & Freq. & word & Freq. & Word & Freq. \\
\hline \hline 1 & qr & 39 & qr & 35 & qr & 24 \\
\hline 2 & code & 36 & code & 25 & code & 18 \\
\hline 3 & system & 31 & using & 19 & smart & 9 \\
\hline 4 & using & 30 & system & 17 & system & 8 \\
\hline 5 & smart & 15 & development & 10 & using & 8 \\
\hline 6 & design & 14 & codes & 10 & consumer & 7 \\
\hline 7 & implementation & 12 & design & 7 & application & 7 \\
\hline 8 & qrcode & 12 & management & 7 & management & 7 \\
\hline 9 & mobile & 11 & method & 6 & model & 7 \\
\hline 10 & information & 10 & image & 6 & perceived & 6 \\
\hline 11 & method & 8 & smart & 5 & development & 5 \\
\hline 12 & management & 8 & mobile & 5 & effects & 5 \\
\hline 13 & application & 8 & fashion & 4 & codes & 5 \\
\hline
\end{tabular}




\begin{tabular}{|c|c|c|c|c|c|c|}
\hline 14 & smartphone & 7 & data & 4 & technology & 5 \\
\hline 15 & authentication & 7 & information & 4 & advertising & 5 \\
\hline 16 & codes & 6 & model & 4 & mobile & 4 \\
\hline 17 & recognition & 6 & efficient & 4 & intention & 4 \\
\hline 18 & image & 6 & recognition & 4 & \multirow{3}{*}{$\begin{array}{l}\text { evaluation/promotion } \\
\text { /school/certification/ } \\
\text { production/phone/ } \\
\text { acceptance/utilization } \\
\text { /information/control } \\
\text { /perception }\end{array}$} & \multirow[t]{3}{*}{3} \\
\hline 19 & digital & 5 & digital & 4 & & \\
\hline 20 & $\begin{array}{l}\text { technology/device } \\
\text { /secure/phone/ } \\
\text { development }\end{array}$ & 4 & $\begin{array}{c}\text { two } \\
\text { dimensional }\end{array}$ & 4 & & \\
\hline \multirow{2}{*}{ No. } & \multicolumn{2}{|c|}{ Engineering } & \multicolumn{2}{|c|}{ Art and physical education } & \multicolumn{2}{|l|}{ Humanities } \\
\hline & word & Freq. & word & Freq. & Word & Freq. \\
\hline 1 & $\mathrm{qr}$ & 29 & $\mathrm{qr}$ & 16 & $\mathrm{qr}$ & 14 \\
\hline 2 & code & 23 & code & 13 & code & 9 \\
\hline 3 & using & 15 & design & 11 & using & 8 \\
\hline 4 & system & 13 & using & 8 & learning & 7 \\
\hline 5 & design & 9 & application & 6 & development & 6 \\
\hline 6 & mobile & 7 & mobile & 5 & education & 4 \\
\hline 7 & smart & 7 & development & 4 & elementary & 3 \\
\hline 8 & management & 6 & model & 4 & materials & 3 \\
\hline 9 & method & 5 & effect & 4 & school & 3 \\
\hline 10 & detection & 5 & marketing & 4 & effects & 3 \\
\hline 11 & digital & 5 & construction & 4 & smart & 3 \\
\hline 12 & robot & 4 & system & 4 & teaching & 3 \\
\hline 13 & development & 4 & use & 4 & mobile & 3 \\
\hline 14 & implementation & 4 & according & 3 & & \\
\hline 15 & algorithm & 4 & textile & 3 & & \\
\hline 16 & phone & 4 & information & 3 & & \\
\hline 17 & camera & 3 & adoption & 3 & & \\
\hline 18 & information & 3 & & & & \\
\hline 19 & sensor & 3 & & & & \\
\hline 20 & $\begin{array}{l}\text { bar/recognition/ } \\
\text { application codes } \\
\text { /code based }\end{array}$ & 3 & & & & \\
\hline
\end{tabular}

\section{(2) Frequency analysis of 'abstract' by subject field}

Table 5 below shows the result of the frequency analysis by subject field for 'abstract', with the top 20 words. In general, the finding of the frequent keywords analysis for the 'abstract' appeared similar with the finding of the analysis for the 'title' of the table. The top three words are fond to be 'qr', 'code', and 'information' for all the three fields, and the next common words are found to be 'system', 'smart', and 'mobile', although there is a bit of differences by field.

As for the specific differences by field, the most common words for the field of 'science and technology' are found to be 'users', 'codes', 'data', 'security', and 'phone', while the most common words for the 'interdisciplinary science' are found to be 'image', 'fashion', 'technology', 'security', and 'barcode'. As far as 'social science' is concerned, the most common words are found to be 'service', 'consumers', 'payment', 'product', and 'management', whereas the most common words for the field of 'engineering' are found to be 'application', 'technology', 'web', and 'marker'. And the most common words in the field of 'art and physical education' are found to be 'marketing', 'technology', and 'recognition', 
while the most common words in field of 'humanities' are found to be 'learning', 'students', 'class', 'university', 'culture', and 'teaching'.

Table 5. Frequency analysis of keywords by subject field for the abstract

\begin{tabular}{|c|c|c|c|c|c|c|}
\hline \multirow{2}{*}{ No. } & \multicolumn{2}{|c|}{ Science and technology } & \multicolumn{2}{|c|}{ Interdisciplinary science } & \multicolumn{2}{|c|}{ Social science } \\
\hline & word & Freq. & word & Freq. & Word & Freq. \\
\hline 1 & $\mathrm{qr}$ & 218 & $\mathrm{qr}$ & 186 & $\mathrm{qr}$ & 181 \\
\hline 2 & code & 185 & code & 157 & code & 131 \\
\hline 3 & information & 147 & information & 80 & information & 86 \\
\hline 4 & system & 114 & codes & 66 & codes & 63 \\
\hline 5 & using & 91 & using & 62 & service & 49 \\
\hline 6 & smart & 74 & system & 55 & system & 44 \\
\hline 7 & mobile & 63 & used & 54 & using & 43 \\
\hline 8 & users & 60 & method & 49 & consumers & 41 \\
\hline 9 & method & 50 & design & 40 & use & 41 \\
\hline 10 & codes & 48 & smart & 39 & payment & 40 \\
\hline 11 & use & 47 & image & 37 & used & 40 \\
\hline 12 & used & 44 & data & 36 & product & 38 \\
\hline 13 & image & 43 & mobile & 33 & management & 35 \\
\hline 14 & data & 41 & use & 32 & factors & 34 \\
\hline 15 & existing & 40 & fashion & 28 & smart & 31 \\
\hline 16 & authentication & 38 & security & 28 & users & 31 \\
\hline 17 & various & 38 & technology & 24 & mobile & 28 \\
\hline 18 & security & 36 & barcode & 23 & technology & 28 \\
\hline 19 & phone & 35 & augmented & 21 & various & 28 \\
\hline 20 & user & 33 & new & 21 & new & 27 \\
\hline \multirow{2}{*}{ No. } & \multicolumn{2}{|c|}{ Engineering } & \multicolumn{2}{|c|}{ Art and physical education } & \multicolumn{2}{|l|}{ Humanities } \\
\hline & word & Freq. & word & & word & Freq. \\
\hline 1 & $\mathrm{qr}$ & 160 & $\mathrm{qr}$ & 139 & $\mathrm{qr}$ & 94 \\
\hline 2 & code & 111 & code & 108 & code & 65 \\
\hline 3 & information & 69 & information & 72 & learning & 65 \\
\hline 4 & using & 63 & design & 70 & students & 39 \\
\hline 5 & system & 49 & codes & 41 & class & 33 \\
\hline 6 & method & 42 & mobile & 40 & education & 33 \\
\hline 7 & smart & 38 & marketing & 40 & university & 30 \\
\hline 8 & mobile & 37 & system & 32 & smart & 36 \\
\hline 9 & codes & 33 & time & 29 & information & 25 \\
\hline 10 & application & 27 & technology & 28 & teaching & 20 \\
\hline 11 & used & 26 & management & 27 & culture & 19 \\
\hline 12 & technology & 26 & use & 25 & group & 18 \\
\hline 13 & image & 25 & used & 24 & use & 18 \\
\hline 14 & service & 23 & recognition & 21 & codes & 18 \\
\hline 15 & web & 22 & construction & 21 & data & 17 \\
\hline 16 & various & 21 & using & 20 & plan & 17 \\
\hline 17 & phone & 21 & smart & 20 & contents/ materials & 16 \\
\hline 18 & data & 20 & users & 20 & $\begin{array}{c}\text { developed } \\
\text { /used/local/poems }\end{array}$ & 15 \\
\hline 19 & marker & 19 & various & 20 & curriculum, mobile & 14 \\
\hline 20 & design & 19 & new/effect & 19 & public/arts/basic & 13 \\
\hline
\end{tabular}




\section{(3) Frequency analysis of 'keyword' by subject field}

Table 6 below presents the findings of the frequency analysis of keywords by subject field for the keyword. As mentioned before, the most frequent keywords are 'qr' and 'code'. But the number of keywords that normally appear in academic papers are mostly $3 \sim 5$, so that the frequency number appeared to be relatively small, compared to the title and abstract. Specifically, for the frequency difference by subject field, more frequent than the words 'qr' and 'qr code' are 'transform' for interdisciplinary science; 'learning' and 'consumer' for social science; and 'learning' and 'education' for humanities.

Table 6. Frequency analysis of keywords by subject field for the keyword

\begin{tabular}{|c|c|c|c|c|c|c|}
\hline \multirow{2}{*}{ No. } & \multicolumn{2}{|c|}{ Science and technology } & \multicolumn{2}{|c|}{ Interdisciplinary science } & \multicolumn{2}{|c|}{ Social science } \\
\hline & word & Freq. & word & Freq. & word & Freq. \\
\hline 1 & code & 15 & $\mathrm{qr}$ & 12 & $\mathrm{qr}$ & 8 \\
\hline 2 & $\mathrm{qr}$ & 12 & code & 10 & learning & 4 \\
\hline 3 & information & 7 & transform & 4 & packaging & 3 \\
\hline 4 & system & 5 & data & 3 & consumer & 3 \\
\hline 5 & image & 5 & system & 3 & code & 3 \\
\hline \multirow{2}{*}{ No. } & \multicolumn{2}{|c|}{ Engineering } & \multicolumn{2}{|c|}{ Art and physical education } & \multicolumn{2}{|c|}{ Humanities } \\
\hline & word & Freq. & word & Freq. & word & Freq. \\
\hline 1 & code & 8 & code & 7 & learning & 7 \\
\hline 2 & qr & 6 & $\mathrm{qr}$ & 6 & education & 4 \\
\hline 3 & bar & 3 & & & arts & 3 \\
\hline 4 & system & 3 & & & $\mathrm{qr}$ & 3 \\
\hline 5 & smart & 3 & & & smart & 3 \\
\hline
\end{tabular}

\subsubsection{Frequency analysis of keywords by year}

\section{(1) Frequency analysis of 'title' by year}

Table 7 shows the findings derived from the top 20 keywords with frequency analysis of keywords by year for the title. The top-ranking keywords by year appeared remarkably similar except for some difference in their ranking. Especially, 'qr' and 'qr code' ranked first and second, respectively since 2010, the frequent keywords are similar. The words 'qr' and 'qrcode' were not considered contents before 2004, so that such words like 'marketing', 'adoption' and 'barcode' were used more than 'qr' related words. But after 2010, there were more frequent words for 'qr' and 'qrcode', and the use of these words 'system', 'smart', 'mobile' and 'phone' increased. But for the years 2016-2020, the frequency ranking increased compared to the time period of 2010-2015, as 'implementation', 'mobile', 'recognition' and 'technology' emerged as new fields of development.

Table 7. Frequency analysis of keywords by year for the title

\begin{tabular}{|c|c|c|c|c|c|c|}
\hline \multirow{2}{*}{ No. } & \multicolumn{2}{|l|}{ 1999-2004 } & \multicolumn{2}{|c|}{ 2010-2015 } & \multicolumn{2}{|c|}{ 2016-2020 } \\
\hline & word & Freq. & word & Freq. & word & Freq. \\
\hline 1 & marketing & 3 & $\mathrm{qr}$ & 95 & $\mathrm{qr}$ & 68 \\
\hline 2 & adoption & 3 & code & 75 & code & 54 \\
\hline 3 & development & 3 & using & 58 & system & 41 \\
\hline 4 & barcode & 3 & system & 35 & using & 37 \\
\hline 5 & brands/cases/quick/ & 2 & smart & 31 & development & 18 \\
\hline 6 & response/system/qr/ & & design & 29 & design & 15 \\
\hline
\end{tabular}




\begin{tabular}{|c|c|c|c|c|c|}
\hline 7 & \multirow{14}{*}{$\begin{array}{l}\text { factors/Korean/scm } \\
\text { /industry/detection/ } \\
\text { performance/model } \\
\text { /algorithm/dimensional }\end{array}$} & mobile & 28 & smart & 13 \\
\hline 8 & & application & 24 & management & 12 \\
\hline 9 & & management & 23 & codes & 12 \\
\hline 10 & & codes & 19 & method & 11 \\
\hline 11 & & information & 17 & Implementation & 11 \\
\hline 12 & & development & 14 & mobile & 11 \\
\hline 13 & & qrcode & 13 & information & 10 \\
\hline 14 & & method & 12 & model & 10 \\
\hline 15 & & phone & 12 & recognition & 10 \\
\hline 16 & & model & 10 & technology & 9 \\
\hline 17 & & implementation & 10 & learning & 9 \\
\hline 18 & & digital & 10 & authentication & 8 \\
\hline 19 & & use & 9 & payment/consumer & 7 \\
\hline 20 & & $\begin{array}{c}\text { service/ } \\
\text { advertising }\end{array}$ & 9 & $\begin{array}{l}\text { /school/education/ } \\
\text { digital/qrcode/color }\end{array}$ & \\
\hline
\end{tabular}

\section{(2) Frequency analysis of 'abstract' by year}

Table 8 below shows the result of the keywords analysis by year for the abstract, with the top 20 words. Even though the high-ranking frequent keywords by year appear almost similar, their rankings are somewhat different. The common aspect throughout all the sample periods is that there are many keywords derived for the 'qr', 'code', and 'information', but before 2009, these words 'marketing', 'system', and 'distribution' were used more than the word 'qr' and 'code'. After 2010, however, the ranking 1 and 2 were 'qr' and 'code', respectively. For the years 2010-2015, the words 'application', 'service', 'technology' were often used, and for the period after 2015, the most used keywords appeared to be 'learning' and 'education'.

Table 8. Frequency analysis of keywords by year for the abstract

\begin{tabular}{|c|c|c|c|c|c|c|}
\hline \multirow{2}{*}{ No. } & \multicolumn{2}{|l|}{ 1999-2009 } & \multicolumn{2}{|c|}{ 2010-2015 } & \multicolumn{2}{|c|}{ 2016-2020 } \\
\hline & word & Freq. & word & Freq. & Word & Freq. \\
\hline 1 & marketing & 28 & $\mathrm{qr}$ & 2567 & $\mathrm{qr}$ & 444 \\
\hline 2 & system & 21 & code & 457 & code & 333 \\
\hline 3 & information & 16 & information & 287 & information & 203 \\
\hline 4 & distribution & 13 & mobile & 183 & using & 156 \\
\hline 5 & $\mathrm{qr}$ & 12 & codes & 164 & system & 156 \\
\hline 6 & factors & 11 & smart & 161 & codes & 112 \\
\hline 7 & apparel & 11 & using & 158 & used & 98 \\
\hline 8 & various & 10 & system & 151 & method & 88 \\
\hline 9 & industry & 11 & use & 119 & learning & 85 \\
\hline 10 & code & 9 & design & 117 & data & 84 \\
\hline 11 & pos & 9 & used & 102 & Smart & 81 \\
\hline 12 & cost & 8 & users & 95 & technology & 68 \\
\hline 13 & production & 8 & application & 92 & use & 63 \\
\hline 14 & barcode & 7 & service & 90 & image & 61 \\
\hline 15 & management & 7 & management & 86 & recognition & 59 \\
\hline 16 & $\begin{array}{l}\text { online/ used/ } \\
\text { time/purpose }\end{array}$ & 7 & method & 84 & various & 57 \\
\hline 17 & application/mobile/ & 6 & technology & 83 & users & 54 \\
\hline 18 & performance/festival & & various & 78 & mobile & 51 \\
\hline 19 & /environment/textile/ & & data & 75 & education & 50 \\
\hline 20 & $\begin{array}{l}\text { products/satisfaction } \\
\text { /response/quick/scm }\end{array}$ & & phone & 74 & security/design & 48 \\
\hline
\end{tabular}




\section{(3) Frequency analysis of 'keyword' by year}

Table 9 below shows the top 20 words derived from the frequency analysis of keywords by year for the keyword. The top-ranking frequent keywords are 'qr' and 'code' throughout all the periods, but there is some difference with the rankings of the keywords by period. For the period before 2009, the keywords were 'scm' and 'sales'; during the period of 2010-2015, the keywords were 'smart', 'mobile', 'system'; and for the period after 2015, the keywords were 'learning' and 'management', so that their rankings were somewhat different depending on the period.

Table 9. Frequency analysis of keywords by year for the keyword

\begin{tabular}{|c|c|c|c|c|c|c|}
\hline \multirow{2}{*}{ No. } & \multicolumn{2}{|c|}{ 1999-2009 } & \multicolumn{2}{|c|}{ 2010-2015 } & \multicolumn{2}{|c|}{ 2016-2020 } \\
\hline & word & Freq. & word & Freq. & Word & Freq. \\
\hline 1 & code/qr/scm & 2 & $\mathrm{qr}$ & 75 & $\mathrm{qr}$ & 47 \\
\hline 2 & /sales/quick/ & & code & 74 & code & 46 \\
\hline 3 & response & & smart & 25 & learning & 15 \\
\hline 4 & & & mobile & 18 & system & 13 \\
\hline 5 & & & system & 13 & $\begin{array}{l}\text { management/ } \\
\text { information/ } \\
\text { response }\end{array}$ & 9 \\
\hline
\end{tabular}

\subsection{Visualization of frequent keywords and the finding of association network analysis for significant words}

\subsubsection{Word cloud}

\section{(1) Word cloud for the titlelabstract/keyword}

According to the findings of visualized word cloud for 'title' and 'abstract', the word ' $q r$ ' occupies central position for the 'title', together with these words 'code' and 'system' surrounding it. Neighboring words 'using', 'smart' and 'design' appear in the vicinity of the word 'qr'. In the case of 'abstract', there appear the words 'information', 'codes', 'using' and 'mobile' around the word 'qr'. For the 'keyword', the words 'learning' and 'system' appear around the word 'qr'.

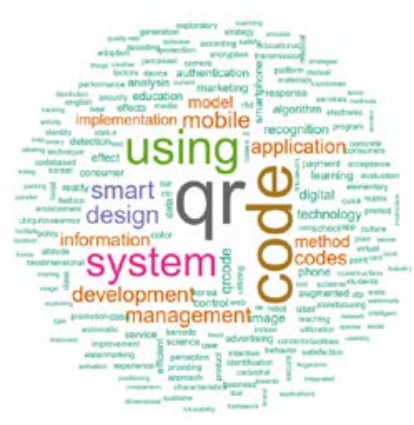

(a) 'title' relevant visualization

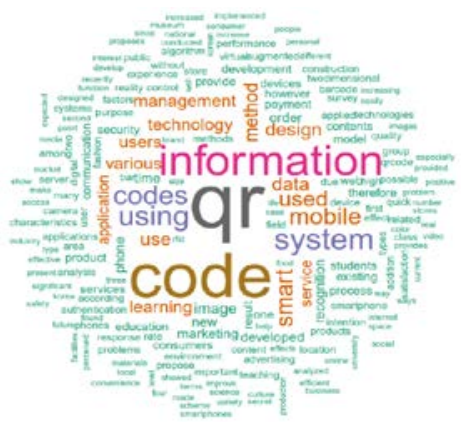

(b) 'abstract' relevant visualization

Fig. 3. Word cloud for QR code

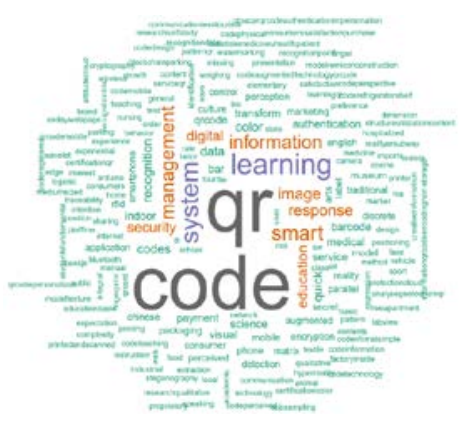

(c) ) 'keyword' relevant visualization 


\section{(2) Word cloud of frequent keywords by subject field for 'title'}

The visualization of the word clouds is derived also by subject field, the same as key word analysis, and overall, the word clouds are formed with the word 'qr' and 'code' in the center. For the subject field of science and technology, the words 'implementation', 'design' and 'smart' appear around the word 'qr'; the words 'development' and 'management' are for interdisciplinary science; the words 'consumer', 'model' and 'application' are for social science; the words 'model' and 'management' are for engineering; the words 'design', 'construction', 'application' and 'mobile' are for art and physical education; and the words 'learning', 'development' and 'education' appear in the central location for humanities.

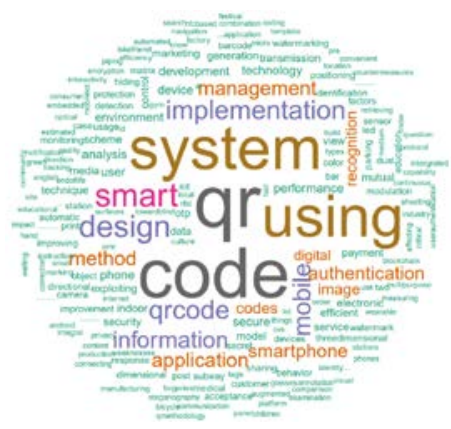

(a) Science and technology

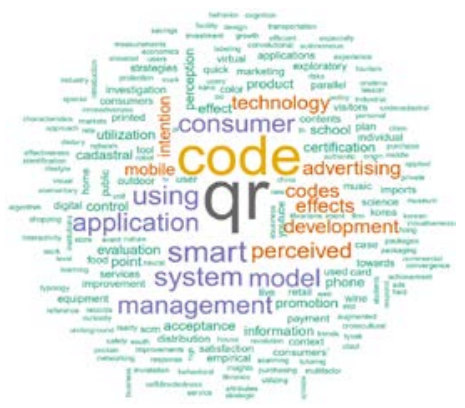

(c) Social science

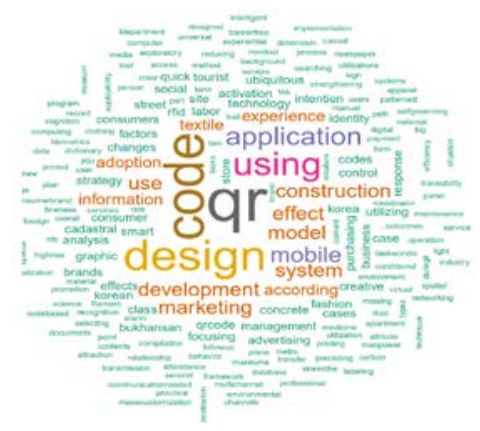

(e) Art and physical education

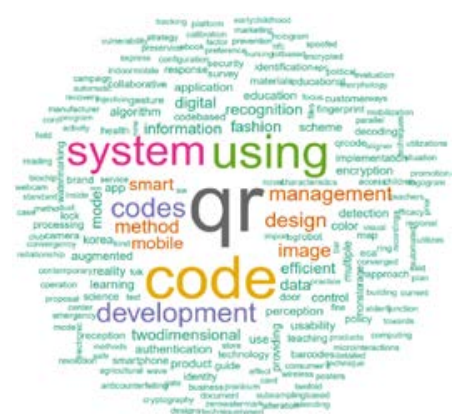

(b) Interdisciplinary science

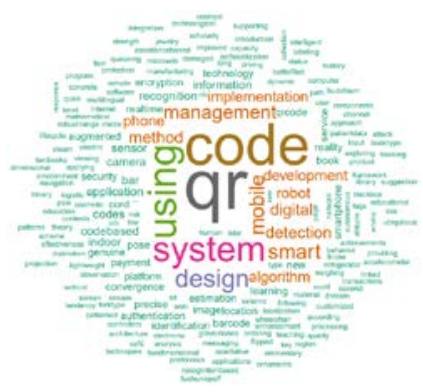

(d) Engineering

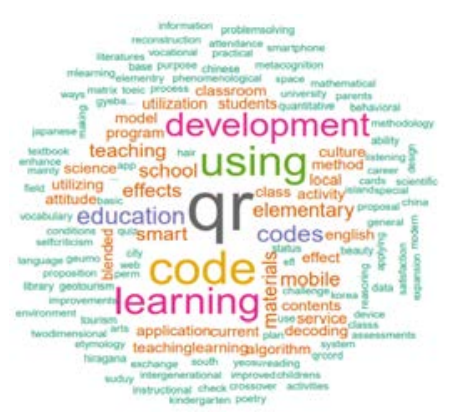

(f) Humanities

Fig. 4. Word cloud of frequent keywords by subject field for the title 


\section{(3) Word cloud of frequent keywords by subject field for 'abstract'}

Fig. 5 below presents the visualization of word clouds of frequent keywords by subject field for the abstract. In figure 5, the words 'qr' and 'code' are featured in center of the word clouds. For the subject field of science and technology, the words 'information', 'system' and 'smart' appear around the word 'qr'; the words 'information' and 'using' are for interdisciplinary science; the words 'information', 'service' and 'payment' are for social science; the words 'information' and 'using' are for engineer; the words 'design', 'information' and 'marketing' are for art and physical education; and the words 'learning', 'students' and 'university' appear in the central location for the humanities.

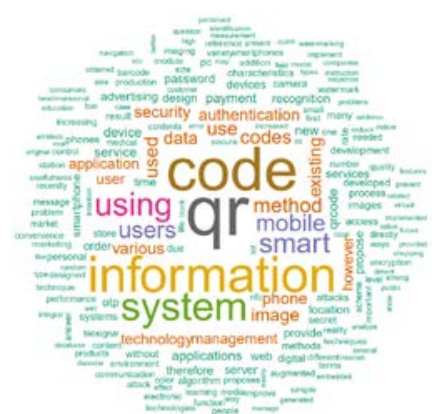

(a) Science and technology

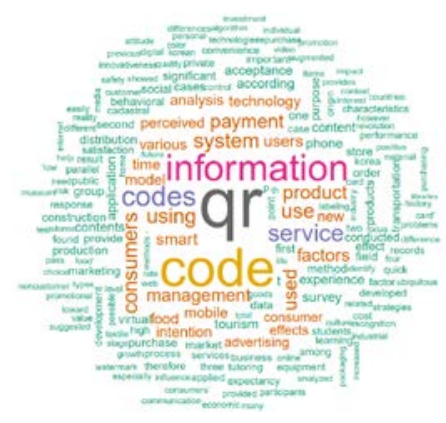

(c) Social science

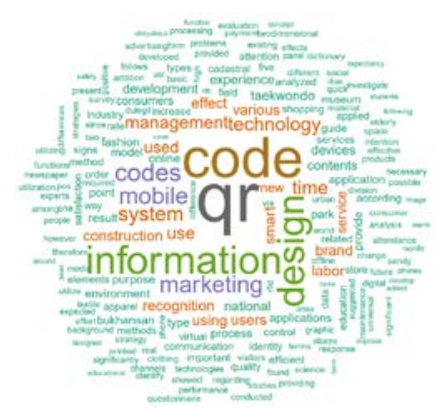

(e) Art and physical education

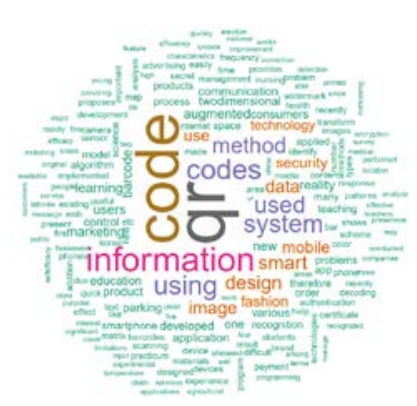

(b) Interdisciplinary science

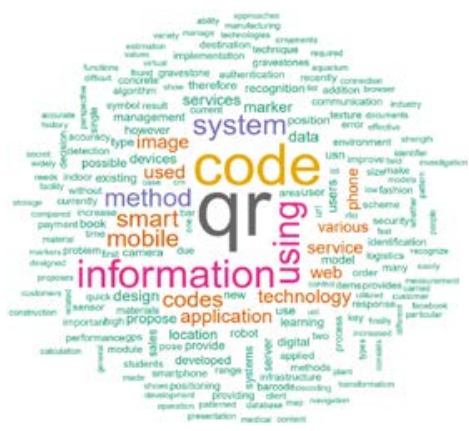

(d) Engineering

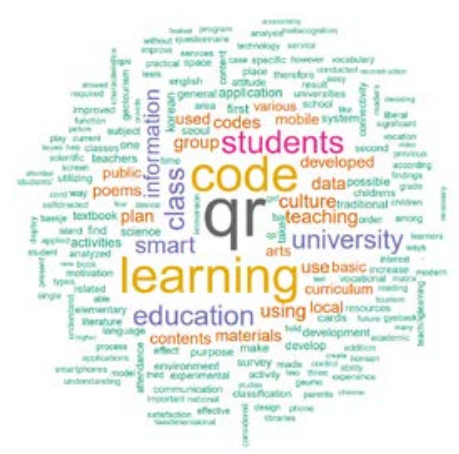

(f) Humanities

Fig. 5. Word cloud of frequent keywords by subject field for the abstract 


\section{(4) Word could of frequent keywords by subject field for 'keyword'}

Fig. 6 shows the word cloud of frequent keywords by subject for the keyword, and the finding are similar with those of 'title' and 'abstract'. But then there are some differences with the words around the central word, for example, the frequency numbers are comparatively smaller for the art and physical education, and that the resulting color and the shape of the word cloud are somewhat different. In the case of science and technology the surrounding key words are 'security' and 'image'. For interdisciplinary science, the surrounding words are 'transform', 'barcode', 'visual' and 'digital'. For the subject field social science, the surrounding words are 'consumer', 'packaging', 'learning', 'satisfaction' and 'marketing'. When it comes to engineering, the surrounding words are 'bar', 'smart', 'management' and 'indoor'. For the subject field of art and physical education, the surrounding words are 'experience', 'recognition' and 'labor', and the surrounding words for the humanities are 'learning', 'education', 'culture', 'school', 'elementary', 'art' and 'English'.

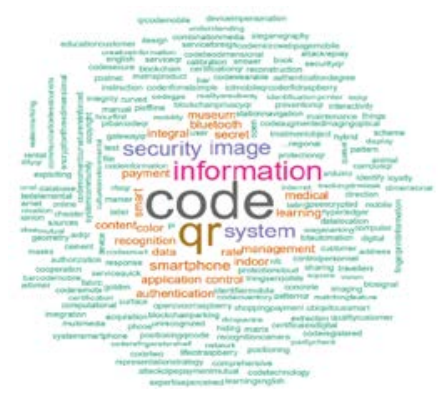

(a) Science and technology

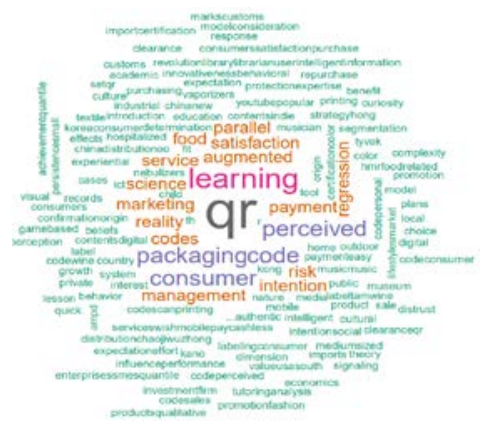

(c) Social science

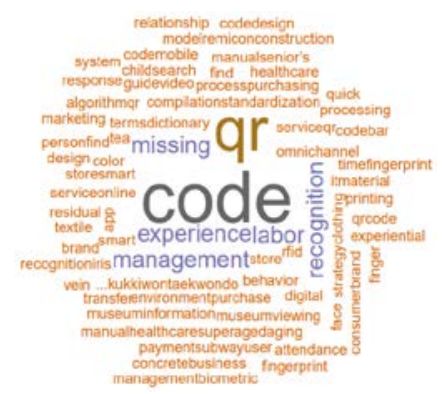

(e) Art and physical education

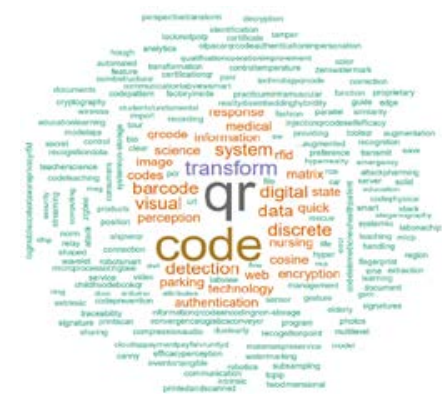

(b) Interdisciplinary science

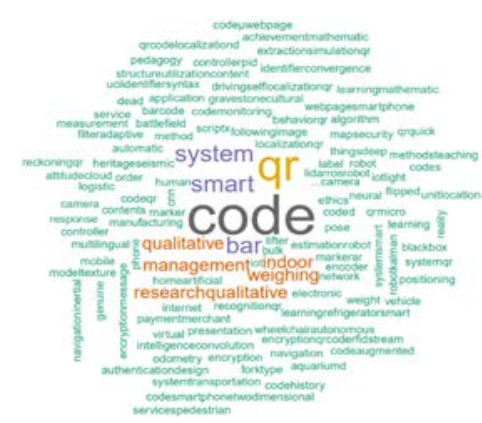

(d) Engineering

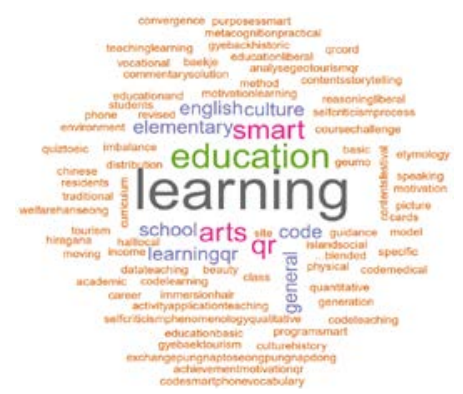

(f) Humanities

Fig. 6. Word cloud of frequent keywords by subject field for the keyword 


\section{(5) Word cloud of frequent keywords by year}

Visualization of the word cloud of frequent keywords by year also produced the same result as mentioned before and Fig. 7 below shows the finding. First, looking into details by period, the frequency of 'qr' and 'code' is relatively smaller for the period 1999-2009, compared to the period after 2010. And for the period 1999-2009, the central words of the cloud are 'marketing', 'barcode', 'distribution', 'srm' and 'sales', while for the period 2010-2014, the central words are 'qr' and 'code', and thereafter similar findings are resulted for the period 2015-2020. For the period 2010-2014, the surrounding words are 'smart', 'application' and 'design', while the surrounding words are 'development', 'recognition', 'learning' and 'image' for the period after 2015.

division

1999-2009

2015-2020

Title
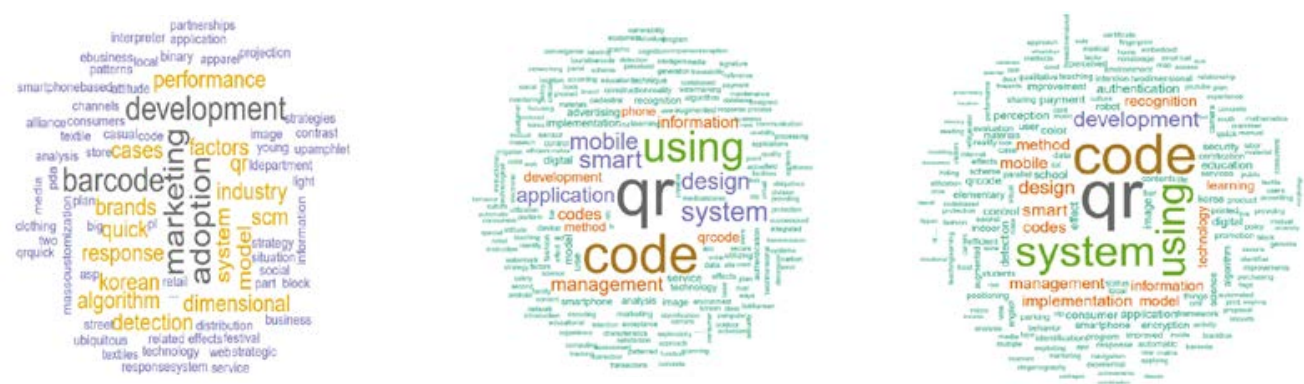

Abstract
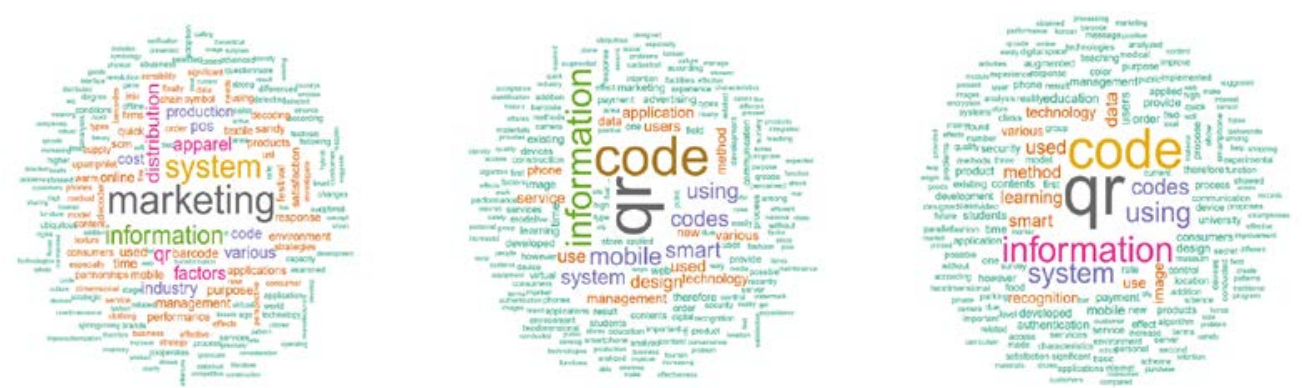

Keyword
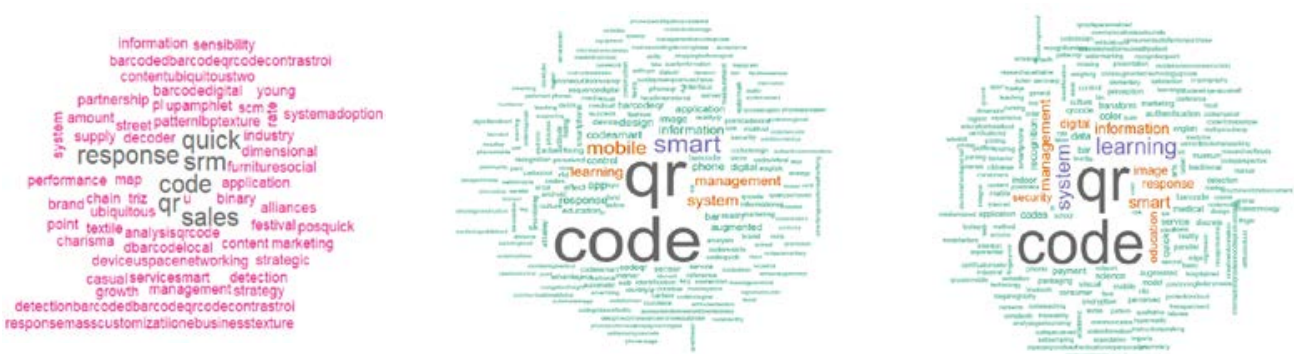

Fig. 7. Word cloud of frequent keywords by year for QR code

\subsubsection{Association Network Analysis}

Network analysis is a method for quantitative examination of relationships among the objects to analyze, and in this study, network analysis is carried out based on the frequency and the words, and the analysis is done for 'title', 'abstract' and 'keyword'. Figure 8 shows the finding, 
and the result is similar with that of keywords analysis. The analysis for the title shows that these words 'qr code', 'service', 'web' and 'network' appear connected each other, but in the analysis for the abstract, these words 'qr', 'code', 'design', 'quick', 'application' and 'smart' appear connected each other. In the case of keyword, the words 'design', 'application', 'smart' appear connected each other through the words 'qr' and 'code' and for 'code', the words 'qr', 'mobile', 'service' and 'bar' appear connected each other.

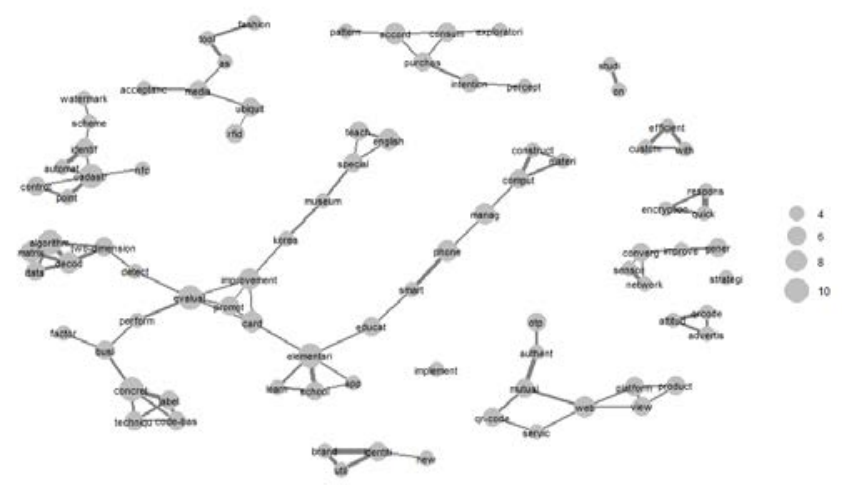

(a)

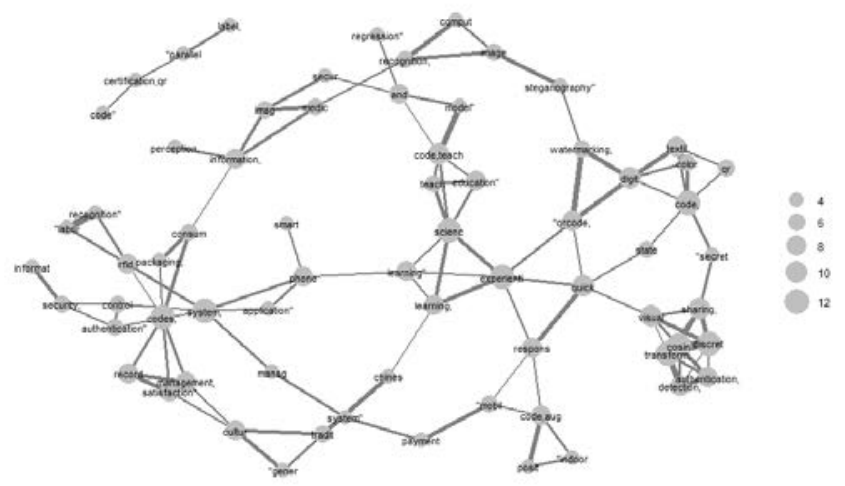

(b)

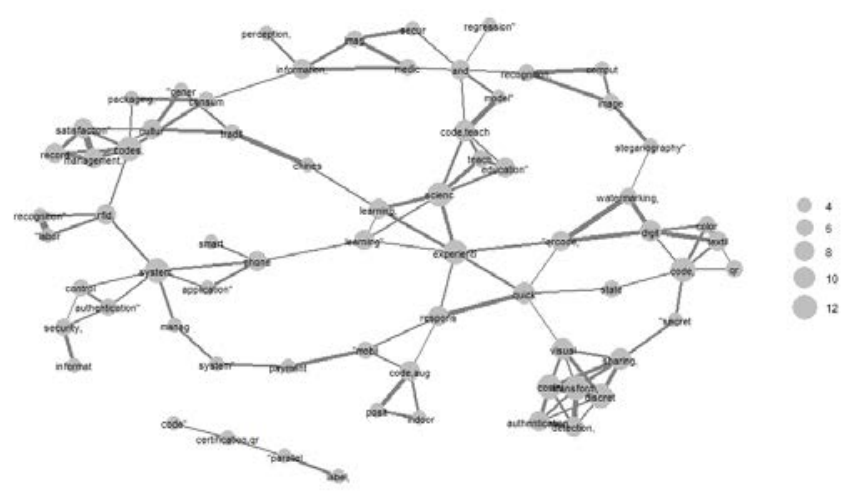

(c)

Fig. 8. Word cloud of frequent keywords by year for QR code 


\section{Conclusion}

With the growth of big data market, studies about big data are also consistently growing, and in connection with recent trend with smartphone and noncontact activities, the use of QR code is rapidly increasing. Existing studies regard QR code kind of bar code or a tool for SCM, so that they take a technical approach limited to certain industry. But in recent years, the applications of QR code expanded into various fields in convergence with others, with utilization of its applications greatly increasing. This study, therefore, recognizes the need for more comprehensive approach to QR code study and uses wider range of analysis method for clearer analysis and direction for future study.

This study analyzes the study trend for last 20 years based on keywords for QR code. The study, therefore, examines the general trend about QR code beyond the limitations of existing studies to certain industry, and takes more comparative approach for more detailed analysis. The data for QR code studies are examined with big data analysis methods to see the study trends. The following are the summary of the findings of the study.

First, QR code study is trending up over time, with the applications expanding into various fields. For example, QR code studies dramatically increased after 2010 and this was due to the developments of IT technologies. Then the number of studies somewhat decreased in 2017, and the trend has been up from 2019. The most significant increase has been observed in the fields of science and technology and social science among other fields. Second, Frequent keywords analysis shows that the keywords ranked in the top half appeared similar by year, even though there is some difference in their rankings. In general, the highest frequency words for the keyword QR code are 'QR' and 'code', and QR code is found to have been used adaptive to subject field. Regarding characteristics by year, QR code was considered just a technology or a tool for logistics before 2010, but then it changed to a converged perspective where QR Code is not utilized in connection with the key word 'information'. Third, the finding of the visualization of frequent words also shows the same result as the frequent keywords analysis. Although visualization has the advantage that it is clear and easy to see the result, it can be difficult to set certain standard for small words or nodes.

Practical implications of this study are as follows: First, studies about QR code should be carried out from a perspective of information communication, rather than a technical perspective. Regarding keywords, QR code in the past was considered just a complementary tool like 'system', 'marketing' and 'barcode', but in the future, QR code can be used as 'information' in connection with 'application', 'using', and 'recognition'. In particular, the derivation of keywords like 'application' and 'payment' means that QR code can be consistently used in our daily life, and the level of the utility will be great as a complementary function or information channel. Second, QR code reflects social issues and phenomena and the function QR code is growing. Prior to 2010 when manufacturing was a big part of the industry, it was used for SCM or as a barcode, but with the advent of the IT era after 2010, the role of QR Code expanded to the fields of information collection and utilization. But with the developments of mobile payment systems after 2015, the boundary of QR code disappeared. But coming to terms with the contactless era, its function as useful tool for learning expanded, and the function of QR code is also expected to develop further in connection with social changes. So, if corporations consider QR code from a technical point of view and social issues or phenomena, practical use of QR code is expected to grow further. So if the Government takes into account these changes in setting their policy, there will be more successful changes to come for the future 
The contributions of the study can be summarized as follows: existing studies on QR code are limited to certain industries, while the study tries various analyses to propose a comprehensive view for expansive applications of QR code. The study helps clearly understand the trend of time series of QR code applications and the current situations of the applications in various fields. The findings of the study provide important points for both corporate companies and the governments that are looking for some direction for policies and regulations for expansive applications of QR code.

The limitations of existing studies are as follows: first, the studies are mainly research papers that deal with QR code theory, so more real case studies and performance studies are necessary in the future studies. Second, existing studies are limited to case studies in South Korea, which is known to have well developed IT infrastructure, that more diverse countries should be included in the future QR code studies. Therefore, multi-country comparative studies of QR code applications in such countries are necessary to understand cultural(social) characteristics by country. Third, text mining and visualization analysis of the frequent words are used for QR code-related data analysis in the study. And additional cross tabulation analysis, correlation analysis and clustering analysis may help solve other practical issues as well.

\section{References}

[1] H. G. Shine, "16 Trillion Dollar Economy for Data and AI, 2030...We Need to Build Innovative Ecosystem,” Aju Business Daily, Korea. [Online]. Available: https://www.ajunews.com/view/20190116095345172, Accessed on: June. 15, 2020.

[2] J. Y. Jeon, “A Study of Korea 'Big Data' Research Trends Using Big Data Analysis,” M.S. thesis, Dept. Business, Hanbat National Univ., Daejoen, Korea, 2019.

[3] M. James, C. Michael, B. Brad, B. Jacques, D. Richard, R. Charles, and H. B. Angela, "Big data: The next frontier for innovation, competition, and productivity,” McKinsey Global Institute, USA. [Online]. Available: https://www.mckinsey.com/business-functions/mckinsey-digital/ourinsights/big-data-the-next-frontier-for-innovation

[4] H. Zhang, M. Song and S. He, "Achieving the Success of Sustainability Development Projects through Big Data Analytics and Artificial Intelligence Capability,” Sustainability, vol. 12, no. 3, pp. 949, 2020. Article (CrossRef Link)

[5] L. X. Song, "A Comparative Study of Factors Affecting the Acceptance of Payment Services Based on QR Code in Korea and China," M.S. thesis, Dept. Management Consulting, Hanyang Univ., Seoul, Korea, 2019.

[6] Statista, "Total revenue of global mobile payment market in 2015, with forecasts from 2016 to 2019," Statista, USA. [Online]. Available: https://www.statista.com/statistics/226530/mobilepayment-transaction-volume-forecast, Accessed on: July. 10, 2020.

[7] G. S. Kim, Big data analysis and meta-analysis, Mapogu, Seoul, Korea: Hannarae, 2015.

[8] Korea Software Technologist Association Big Data Strategy Institute co., Big Data Introduction, Paju, Korea, KwangmoonKag, 2019.

[9] Doug Laney, “3D Data Management: Controlling Data Volume, Velocity, and Variety," META Group, Stamford, CT, USA. [Online]. Available: https://pdfcoffee.com/ad949-3d-datamanagement-controlling-data-volume-velocity-and-varietypdf-pdf-free.html, Accessed on: July. 15, 2020.

[10] S. Kaisler, F. Armour, J. A. Espinosa and W. Money, "Big data: Issues and Challenges Moving Forward," in Proc. of Annual Hawaii International Conference on System Sciences, vol. 46, no. 2, pp. 1060-3425, 2013. Article (CrossRef Link)

[11] E. Dumbill, “Making Sense of Big Data," Big Data, vol. 1, no. 1, pp. 1-2, Feb. 2013. Article (CrossRef Link) Making Sense of Big Data - PubMed (nih.gov) 
[12] M. Jaems, C. Michael, B. Brad, B. Jacques, D. Richard, R. Charles and H. B. Angela, "Big data: The next frontier for innovation, competition, and productivity,” McKinsey Global Institute, USA. [Online]. Available: https://www.semanticscholar.org/paper/Big-data\%3A-The-next-frontier-forinnovation\%2C-and-Manyika/91b63db746becca15090963a8990dfe2b5103799, Accessed on: July. 9, 2020.

[13] R. Addo-Tenkorang, P. T. Helo, "Big data applications in operations/supply-chain management; A literature review,” Computers \& Industrial Engineering, vol. 101, pp. 528-543, 2016. Article (CrossRef Link)

[14] S. G. Cho and S. B. Kim, "Finding Meaningful Pattern of Key Words in IIE Transactions Using Text Mining,” Journal of the Korean Institute of Industrial Engineers, vol. 38, no. 1, pp. 67-73, 2012. Article (CrossRef Link)

[15] Y. B. Jung and E. S. Park, "Keyword Analysis of two SCI Journals on Rock Engineering by using Text Mining,” Tunnel and Underground Space, vol. 25, no. 4, pp. 303-319, 2015. Article (CrossRef Link)

[16] TDWI, "Big Data Analytics," TDWI Best Practices Report. [Online]. Available: https://tdwi.org/research/2011/09/best-practices-report-q4-big-dataanalytics.aspx?tc=page0\&tc=assetpg\&tc=page0, Accessed on: July. 10, 2020.

[17] D. R. Hwang and G. E. Hwang, "Examining of Semantic Map of Humanities Contents through Semantic Network Analysis,” The Human Contents, vol. 0, no. 43, pp. 229-255, 2016. Article (CrossRef Link)

[18] S. LaValle, E. Lesser, R. Shockley, M.S. Hopkins and N. Kruschwitz, "Big Data, Analytics and the Path from Insights to Value,” MIT Sloan Management Review, vol. 52, no. 2, pp. 21-32, 2013. Article (CrossRef Link)

[19] D. Loshin, Big Data Analytics: From strategic planning to enterprise integration with tools, techniques, NoSQL, and graph, Morgan Kaufmann Publishers, USA, 2014.

[20] J. Zakir, T. Seymour and K. Berg, “Big data analytics,” Issues in Information Systems, vol. 16, no. 2, pp. 81-90, 2015. Article (CrossRef Link)

[21] S. Tiwari, H.M. Wee and Y. Daryanto, "Big data analytics in supply chain management between 2010 and 2016: Insights to industries,” Computers \& Industrial Engineering, vol. 115, pp. 319330, Jan. 2018. Article (CrossRef Link)

[22] P. Tambe, "Big Data Investment, Skills and Firm Value,” Management Science, vol. 60, no. 6, pp. 1452-1469, 2014. Article (CrossRef Link)

[23] E. Brynjolfsson and K. McElheran, "The Rapid Adoption of Data-Driven Decision Making," American Economic Review, vol. 106, no. 5, pp. 133-139, 2016. Article (CrossRef Link)

[24] J. Y. Ahn, K. B. Ahn and M. Song, "Text Mining Driven Content Analysis of Ebola on News Media and Scientific Publications," Journal of the Korean Society for Library and Information Science, vol. 50, no.2, pp. 289-307. 2016, Article (CrossRef Link)

[25] D. I. Yook, “Text Mining-Based Analysis for Research Trends in Vocational Studies,” Journal of the Korea Academia-Industrial Cooperation Society, vol. 18, no.3, pp. 586-599, 2017. Article (CrossRef Link)

[26] M. B. Kwon, "A Corpus Analysis of the Lexical Characteristics of Tourism Research Paper Abstracts and the Research Trends,” Linguistic Society, vol. 24, no. 3, pp. 1-21, 2017. Article (CrossRef Link)

[27] N. K. Jang and M. J. Kim, "Research Trend Analysis in Fashion Design Studies in Korea using Topic Modeling,” Journal of Digital Conversion Study, vol. 15, no. 6, pp. 415-423, 2017. Article (CrossRef Link)

[28] D. N. Kim, K. S. Hong, J. H. Go and J. H. Jeon, “Analysing the Research Trend of Aerospace Field,” Journal of Industrial Innovation, vol. 33, no. 4, pp. 193-226, 2017. Article (CrossRef Link)

[29] S. H. Lee, "Factors Influencing the Pre and Post Acceptance Behavior of QR code users,” Journal of Korea Contents Association, vol. 11, no. 12, pp. 136-144, 2011. Article (CrossRef Link)

[30] P. Fontelo, F. Liu and E. G. Ducut, “QR code for medical information uses,” in Proc. of AMIA Symposium, vol. 2, pp. 945, Nov. 2008. Article (CrossRef Link) 
[31] G. John, “Quark Marketing Services \& QR Codes,” Quick Printing, vol. 33, no. 5, pp. 18-21, Feb. 2010. Article (CrossRef Link)

[32] T. Y. Liu, T. H. Tan and Y. L. Chu, "QR Code and Augmented Reality-Supported Mobile English Learning System,” Lecture Notes in Computer Science, no. 5920, pp. 37-52, 2010. Article (CrossRef Link)

[33] Z. Zhang, J. Yue and Z. Li, "A QR Code Traceability System for the Aquatic Products Quality Based on Smartphone," Sensor letters, vol. 12, no. 3-4, pp. 563-568, 2014. Article (CrossRef Link)

[34] S. F. Yuan and Z. Zhang, "Improved Binarization Method of QR Code Mobile Terminal," Applied Mechanics and Materials, vol. 518, pp. 374-380, 2014. Article (CrossRef Link)

[35] S. Puchong and K. Pramote, "Internet Banking Transaction Authentication Using Mobile OneTime Password and QR Code,” American Scientific Publishers, vol. 21, no.10, pp. 3189-3193, 2015. Article (CrossRef Link)

[36] C. T. Bruce Ho, J. M. Denis Yang, "Factors affecting users' mobile technology usage intentions: an example of QR code scanning for mobile commerce," International Journal of Mobile Communications, vol.15, no. 2, pp.185-209, 2017.

[37] S. Gao, X. Yang, H. Guo and J. Jing, "An Empirical Study on Users' Continuous Usage Intention of QR Code Mobile Payment Services in China,” International Journal of E-Adoption, 10, 18-33, 2018.

[38] L. Lou, Z. Tian and J. Koh, "Tourist Satisfaction Enhancement Using Mobile QR Code Payment: An Empirical Investigation,” Sustainability, vol. 9, no. 7, pp. 1-14, 2017. Article (CrossRef Link)

[39] Y. Peng, L. Zhang, Z. Song, J. Yan, X. Li and Z. Li, "A QR code-based tracing method for fresh pork quality in cold chain,” Journal of food process engineering, vol. 41, no. 4, pp. 1-11, 2018.

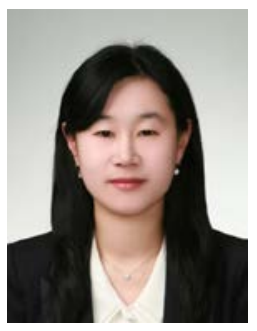

EunJi Lee received the B.S. degree in Statistics from Yonsei University, Seoul, South Korea, 2003. She received the M.S. and Ph.D. degrees in Business Administration from Kyunghee University, Korea, in 2005 and 2011, respectively. Dr. Lee joined the consultant and researcher of Researcher \& Senior Consultant at Bureauveritas corporation and Korea Standard Association Consulting in Seoul, Korea from 2005 to 2009 respectively. She is currently a university lecturer in the Global Leadership College, Yonsei University, Korea in 2019. She is interested in parallel statistics, service company and global business.

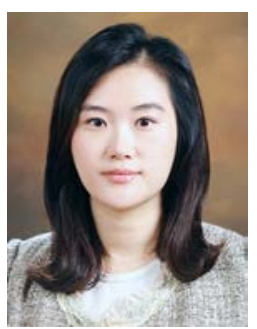

Jikyung Jang received her Ph.D. degree in Business Administration from Pusan National University, Busan, South Korea, in 2010. She served as a Certified Tax Accountant at JoongChoo Accounting Corporation from 2004 to 2008. She is currently an associate professor at Department of Business Administration at Dongseo University in Busan, South Korea. Her current research interests include Earnings Management, Accounting Information, Tax Avoidance, and Big Data Analysis. 